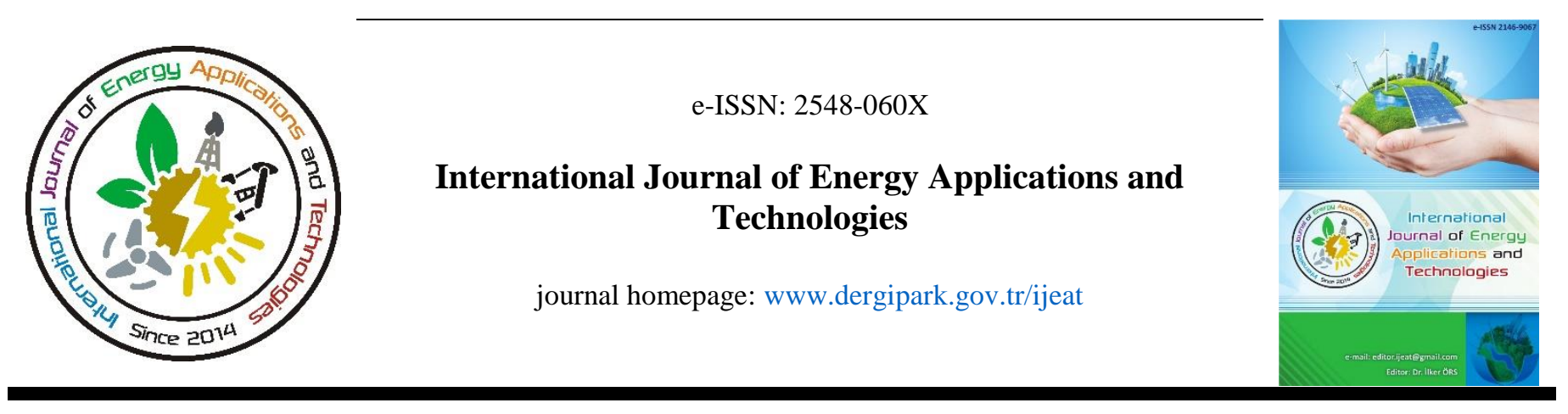

Original Research Article

\title{
Thermal efficiency evaluation of an organic Rankine cycle with n-pentane as working fluid
}

hosted by Jurkish Oulnal Park

\author{
Sadık Ata ${ }^{1 *}$, Ali Kahraman ${ }^{2}$, Remzi Şahin ${ }^{1}$ \\ ${ }^{1}$ Mechanical Engineering Department, KTO Karatay University, Faculty of Engineering, TURKEY \\ ${ }^{2}$ Energy Systems Engineering Department, Necmettin Erbakan University, Faculty Of Engineering and Architecture, TURKEY
}

\section{ARTICLE INFO \\ * Corresponding author sadik.ata@karatay.edu.tr \\ Received July 17, 2018 \\ Accepted May 20, 2019 \\ Published by Editorial Board Members of IJEAT \\ C) This article is distributed by Turk Journal Park System under the CC 4.0 terms and conditions.}

doi: 10.31593/ijeat.444464

\begin{abstract}
In this study, the effect of evaporation pressure and superheating temperature on system performance was determined in the Organic Rankine Cycle (ORC) model designed using npentane fluid. EES (Engineering Equation Solver) software design using 9 different conditions have been identified. In the first model where the evaporation pressure was between $250 \mathrm{kPa}$ and $400 \mathrm{kPa}$, the efficiency of ORC was determined under five different constant superheating temperatures. In the second model, the evaporation pressure was determined as 4 different constant values and the temperature of the superheating temperature was changed between $0{ }^{\circ} \mathrm{C}$ and $20{ }^{\circ} \mathrm{C}$. N-pentane, which is widely used in ORC geothermal applications, has been determined as working fluid. Within the scope of geothermal applications, the heat source temperature is assumed to be constant at $120^{\circ} \mathrm{C}$. Condenser pinch point temperature difference is taken as $3^{\circ} \mathrm{C}$. As a result of the study, the data obtained from two different models were evaluated separately. When the superheating temperature is not applied, turbine work increases by $35 \%$ as the evaporation pressure rises from $250 \mathrm{kPa}$ to $400 \mathrm{kPa}$. In addition, thermal efficiency also increased by $26 \%$. When the evaporation pressure is constant at $250 \mathrm{kPa}$, the turbine work increased by $7.32 \%$ due to the increase of the superheating temperature from $0{ }^{\circ} \mathrm{C}$ to $20{ }^{\circ} \mathrm{C}$. However, with the increase of heat input, thermal efficiency decreased by $1.38 \%$. In the ORC system using $\mathrm{N}$-pentane, it is stated that application of the superheating temperature reduces the performance. In the study, the highest thermal efficiency (12.59\%) was achieved at the evaporation pressure of $400 \mathrm{kPa}$ in the case of not applying superheating. The main purpose of this study was to evaluate the thermal efficiency of n-pentane fluid used in the geothermal applications of ORC under different evaporation pressure and overheating temperatures.
\end{abstract}

Keywords: organic Rankine cycle (ORC); thermal efficiency; superheating; n-Pentane

\section{Introduction}

Organic Rankine Cycles work on the same principle as Rankine cycles in terms of thermodynamics. Rankine cycles are conventional steam turbines where electricity is generated from the heat and require high temperature and pressure resources depending on operating conditions. Unlike the Rankine cycle, the organic Rankine cycle is a power system in which organic fluids are used instead of water which is fluid in low temperature ranges. Because of the evaporation of the organic fluid at lower temperatures, electric fields are possible from lower temperature heat sources. Thanks to these properties, energy production can be used more efficiently in non-economic industrial waste heat, geothermal heat, solar energy, oil and gas fields [1].

Kaska [2] have analyzed energy and exergy analysis of waste heat-driven Organic Rankine Cycle. The effect of the evaporator/condenser pressure, superheating and sub-cooling on energy and exergy efficiency is shown. The order of the 
components with the most exergy destruction is evaporator, turbine, condenser and pump. It has been found that the effect of the evaporative pressure on both energy and exergy efficiency is great. Lecompte et al. [3], studied the second law-based thermodynamic performance analysis for nonsuperheated subcritical Organic Rankine cycle using the zeotropic mixture as the organic fluid. REFPROP9.0 provides thermo-physical data of zeotropic mixture and pure fluids. R245fa-pentane, R245fa-R365mfc, isopentaneisohexane, isopentane-cyclohexane, isobutane-isopentane and pentane-hexane selected as zeotropic mixture. The second law is used as the optimization criterion. Compared with pure fluids, the efficiency of the second law was increased by $7.1 \%$ and $14.2 \%$. Le et al. [4], optimized the performance of a supercritical ORC system with low temperature power generation using fluids with low global warming potential (GWP) as the organic fluid. Commonly used R134a fluid is used for comparison. Hot water at $150^{\circ}$ $\mathrm{C}$ and 5 bar pressure was used as the heat source medium. The thermodynamic performance comparison of the supercritical Organic Rankine Cycle was performed using the Ranking method and the exergy method using different organic fluids. For the highest available efficiency of the system; R152a was obtained for $11.6 \%$ for simple cycle and $13.1 \%$ for regenerative cycle. The best organic fluids for system efficiency optimization are R32 for simple cycle and R152a for regenerative cycle. Javanshir and Sarunac [5], assessed the thermodynamic performance of the simple subcritical and super-critical Organic Rankine Cycle. They have analyzed organic fluids over various operating conditions and have made the best fluid choice. Ebsilon Professional software was used for thermodynamic modeling. The efficiency of isentropic fluids is higher than that of dry and wet fluids.

The design of the small scale Organic Rankine cycle system and the control conditions for low grade heat recovery applications were conducted through experimental investigations by $\mathrm{Li}$ et al. [6]. For the ORC system, the $\mathrm{R} 245 \mathrm{fa}$ was selected as the organic fluid. The effects of the condenser cooling water temperature and the performance of the hot R245fa at the turbine inlet and on the cycle have been measured and analyzed. ORC expansion is guaranteed with some security operations. The thermal expansion of the heated R245fa was controlled to remain constant. In the constant heat source parameters (temperature and flow rate), turbo expander net output power and cycle efficiency are reduced with coolant water temperature. Under the specified specific test conditions, when the cooling water temperature was set at $23.0^{\circ} \mathrm{C}$ and the pressure ratio was set at 7.3 , the maximum turboexpanding power generation was able to achieve $5.405 \mathrm{~kW}$.
Hydrofluorinated ethers containing HFE7000, HFE7100 and HFE7500 were analyzed using the Organic Rankine Cycle as the organic fluid under fixed external conditions by Wang et al. [7]. They developed a computer program to compare the first and second efficiency laws, net power output, turbine inlet temperature increase and turbine size factor. Thermodynamic analyzes of the organic fluids tested under the turbine inlet temperature were performed using the Engineering Equation Solver (EES) computer program. It was found that HFE7000 produces maximum thermodynamic efficiency and gives the best result in terms of net power under given conditions. The HFE7000 organic fluid has been found to have the lowest turbine size compared to HFE7100 and HFE7500. In the ORC, HFE7000 has been proposed to be used as a organic fluid for low temperature heat conversion. Li et al. [8] have used the R1234ze(E) fluid for a $100-200^{\circ} \mathrm{C}$ heat source to optimize critical and transcritical Organic Rankine cycles and thermodynamic performance analyzes. The thermo-physical properties of R1234ze(E) fluid were calculated using REFPROP. It has been found that the trans critical ORC system has higher system efficiency than the subcritical ORC system, but has lower heat absorption capacity. The maximum power output of R1234ze (E) is $31.4 \%$ higher than R245fa and $25.8 \%$ higher than R600 for $100-167^{\circ} \mathrm{C}$ heat source.

Feng et al. [9] investigated the test and study characteristics of the Organic Rankine cycle using a scroll compressor. R123 was selected as the working fluid. Based on the measured temperatures and pressures, entropy and entropy corresponding to each state were obtained with NIST REFPROP. With the help of experimental data, the pump power consumption, isantropic efficiency and recycle rate were obtained as $0.21-0.32 \mathrm{~kW}, 26.76-53.96 \%$ and $14-32 \%$ respectively. When the heat transfer coefficient of the evaporator and the condenser is 200-400 and 450-2000 $\mathrm{W} / \mathrm{m} 2 \mathrm{~K}$ respectively, it is found that the expansion isantropic and generator efficiency are in the range of $69.10-85.17 \%$ and $60-73 \%$ respectively.

In this study, the role of evaporation pressure and superheating temperature in ORC performance was determined by the thermodynamic design model. In the thermodynamic design model prepared with EES, n-pentane was selected as the organic fluid. In geothermal power plants with ORC technology, the effect of the n-pentane fluid, which is widely used as organic fluid, on the system has been determined. Within the scope of the study two different models were created. In the first model, the superheating temperature is kept constant to detect the effect of the evaporation pressure on the system. In the second model, the results of the change in superheating temperature under constant evaporation pressure were examined. 
In both models, the amount of heat requirement, work done by the turbine, turbine inlet-outlet temperature and thermal efficiency values were determined. In the study, considering the thermo-physical properties of the n-pentane fluid, the input parameters were determined so as not to be in contradiction with the laws of thermodynamics. The main purpose of this work is to determine the effect of the npentane fluid on the system performance, which is used extensively in the ORC application field, together with the evaporation pressure and superheating temperature changes.

\section{Material and Method}

The working principle of the Organic Rankine Cycle and the T-s diagram are given in Fig.1.

1-2: Isentropic compression in the pump, 2-3: Heat input at constant pressure in evaporator,

3-4: Isentropic expansion in turbine, 4-1: Heat output at constant pressure in condenser.
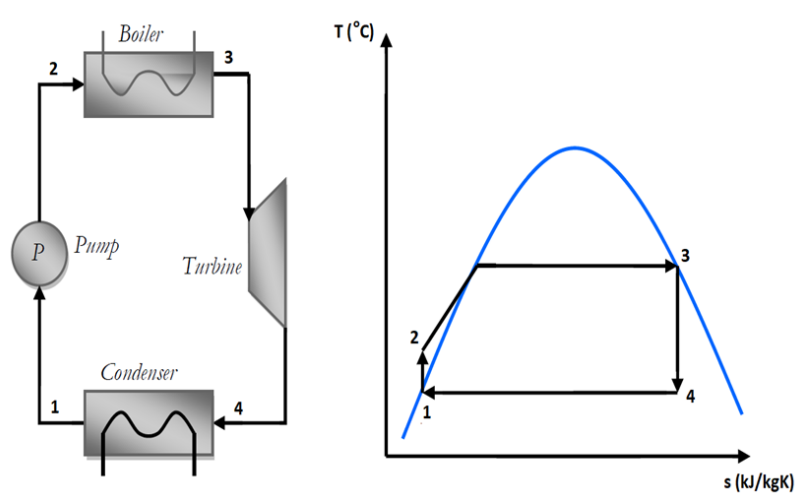

Fig. 1. ORC Working principle and T-s diagram [10]

The physical and environmental properties of the n-pentane fluid determined in the study are given in Table 1 . It is noteworthy that it has a low boiling temperature and that ODP value which is important from environmental care is 0 .

Table 1. Physical and environmental properties n-pentane used in design [11]

\begin{tabular}{lc}
\hline Properties & n-pentane \\
\hline ds/dT & Dry fluid \\
Molecular Mass $(\mathbf{g} / \mathbf{m o l})$ & 72.15 \\
Normal Boiling Point $\left({ }^{\circ} \mathbf{C}\right)$ & 36.1 \\
Critical Temperature $\left({ }^{\circ} \mathbf{C}\right)$ & 196.6 \\
Critical Pressure $(\mathbf{M P a})$ & 3.37 \\
ASHRAE 34 safety group & $\mathrm{A} 3$ \\
ODP & 0 \\
GWP & 20 \\
\hline
\end{tabular}

When the slope of the saturation curves in the T-s diagrams of the fluids is positive, it is called the dry fluid. The T-s diagram of the n-pentane fluid which is a dry fluid is given in Fig.2.

Within the scope of the study two different models were created. For each of the prepared models, 9 different thermodynamic states were analyzed. For all situations; pump inlet temperature $20^{\circ} \mathrm{C}$, cooling water temperature 17
${ }^{\circ} \mathrm{C}$, hot source temperature $120{ }^{\circ} \mathrm{C}$. In addition, the isentropic efficiency of the turbine and pump is taken as $85 \%$.

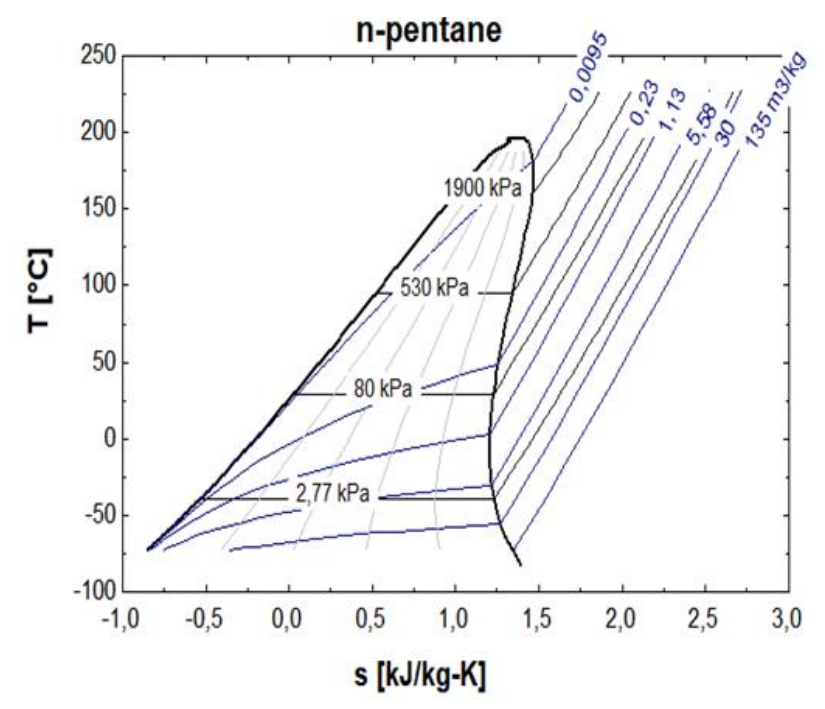

Fig. 2. T-s diagram of n-pentane fluid

Thermodynamic design models were created using EES. The equations for energy analysis are given in Equation 1-9. These equations were processed in EES program and energy analysis was started. In the program, the values which are accepted as fixed first are indicated. Figure 3 presents a flow diagram describing the working principle of two different models. Energy analysis was performed based on this flow diagram.

\section{Energy Analysis:}

$\left(Q_{\text {in }}-Q_{\text {out }}\right)+\left(W_{\text {in }}-W_{\text {out }}\right)=h_{e}-h_{i}$

Pump $(q=0)$

Wpump, in $=h_{2}-h_{1}$

$W_{\text {pump }, \text { in }}=v\left(P_{2}-P_{1}\right)$

where

$h_{1}=h_{f} @ P_{1}$ and $v \cong v_{1}=v_{f} @ P_{1}$

Boiler $(\mathrm{w}=0)$ :

$Q_{\text {in }}=h_{3}-h_{2}$

Turbine $(q=0)$ :

$W_{\text {türbin }}=h_{3}-h_{4}$

Condenser $(\mathrm{w}=0)$ :

$Q_{\text {out }}=h_{4}-h_{1}$

The energy efficiency of the Rankine cycle

$\eta_{\text {th }}=\frac{W_{\text {net }}}{Q_{\text {in }}}=1-\frac{Q_{\text {out }}}{Q_{\text {in }}}$

where

$W_{\text {net }}=Q_{\text {in }}-Q_{\text {out }}=W_{\text {turb }, \text { out }}-W_{\text {pump }, \text { in }}$ 


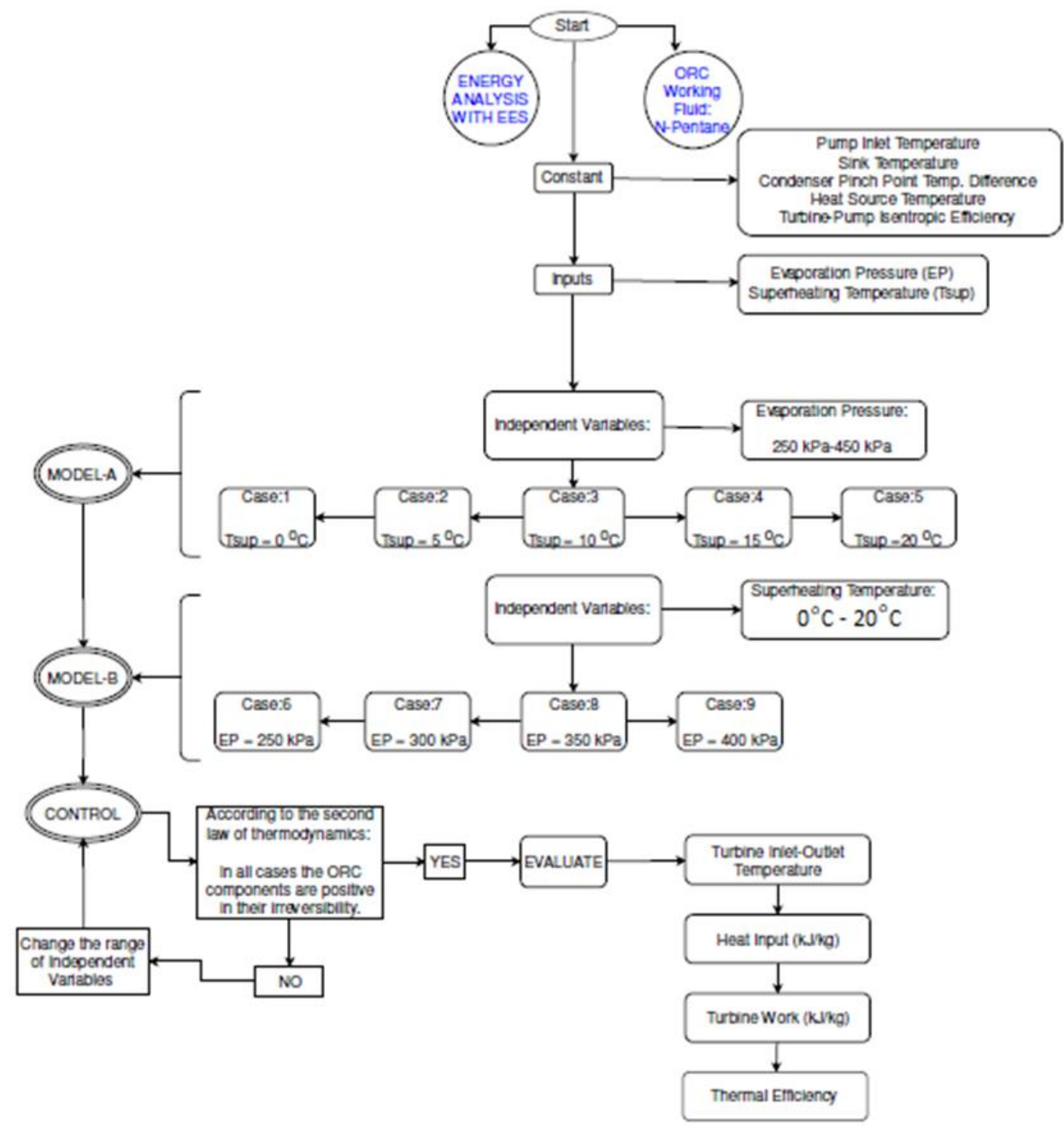

Fig. 3. Flow chart for Simulation of ORC System with N-Pentane

The purpose of this study is to demonstrate the effect of evaporation pressure and superheating temperature on ORC performance. In determining the amount of heat required in the system, the importance of the evaporation pressure is specified. In evaporative pressure change, a system that does not have a superheating temperature and a system that has a fixed superheating temperature of $5,10,15$, and $20{ }^{\circ} \mathrm{C}$ have been examined. Secondly, the influence of the superheating temperature change on the system under fixed evaporation pressures of 250-300-350 and $400 \mathrm{kPa}$ was determined. The performance of the n-pentane fluid, which is used in ORC application field, at different evaporation pressures and superheating temperatures, has been tried to be explained by energy analysis.

\section{Model Validation}

The data obtained in order to determine the accuracy of the simulation study with EES were compared with another study (Ref. [10]) in the same working conditions. N-pentane fluid was used in the study. Hot source temperature $90{ }^{\circ} \mathrm{C}$, sink temperature $28{ }^{\circ} \mathrm{C}$, evaporator temperature $75{ }^{\circ} \mathrm{C}$, condenser temperature $35{ }^{\circ} \mathrm{C}$, pump efficiency $80 \%$, the total efficiency (mechanical+isentropic) of the turbine $44 \%$ is taken. The results of two studies in the same study parameters are given in Table 2 . The results are very close to each other.

Table 2. Comparison between the present results and those from Ref. [10].

\begin{tabular}{lcc}
\hline Performance parameters & Ref. [10] & Present Work \\
\hline Working Fluid & n-Pentane & n-Pentane \\
Heat Input [kJ/kg] & 421.41 & 421.8 \\
Turbine Work [kJ/kg] & 18.86 & 18.84 \\
Thermal efficiency [\%] & 4.367 & 4.359 \\
\hline
\end{tabular}

\section{Results and Discussion}

In this study, the input parameters were determined for the selected n-pentane fluid by checking the compatibility with the second law of thermodynamics. A much lower evaporation pressure range was determined compared to the evaporation pressures of the classic Rankine cycle.

I) MODEL-A

In the first model, the system performance was examined by changing the evaporation pressure between $250 \mathrm{kPa}$ and 400 $\mathrm{kPa}$. The thermodynamic design model has been prepared 
separately for the following 5 different situations. For all cases, the amount of heat required for the system, turbine work, turbine inlet-outlet temperatures and thermal efficiency values are determined separately. With 75 input numerical test values, 375 numerical output values for each case were obtained. The analysis of model A was done with a numerical output value of 1875 for 5 different situations in total. These situations are;

- No superheating

- $5^{\circ} \mathrm{C}$ degree of superheat

- $10^{\circ} \mathrm{C}$ degree of superheat

- $15^{\circ} \mathrm{C}$ degree of superheat

- $20^{\circ} \mathrm{C}$ degree of superheat

Figure 4 shows the effect of evaporation pressure change on the amount of heat requirement for different superheating temperatures. In all cases, as the evaporation pressure increases, the system seems to require more heat. As the evaporation pressure increased from $250 \mathrm{kPa}$ to $400 \mathrm{kPa}$, the heat requirement increased by $28 \mathrm{~kJ} / \mathrm{kg}$ for a no superheating system, while it increased by $31 \mathrm{~kJ} / \mathrm{kg}$ for a system with constant $20{ }^{\circ} \mathrm{C}$ degree of superheat.

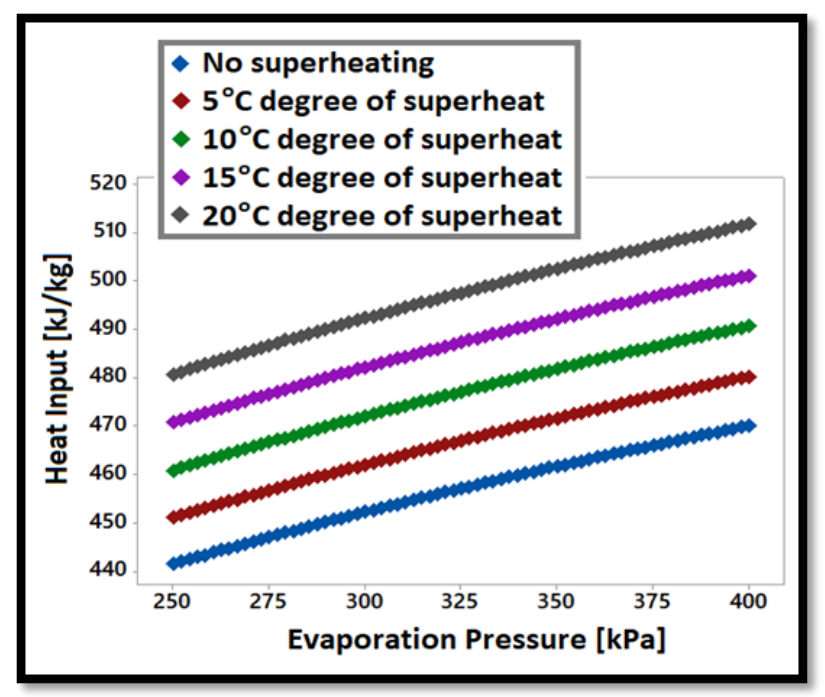

Fig. 4. Change of heat input with evaporation pressure

Figure 5 shows the effect of evaporation pressure change on turbine inlet temperature for different superheating temperatures conditions. In all cases, as the evaporation pressure increases, the turbine inlet temperature increases. When the system without superheating is examined, the turbine inlet temperature for the $250 \mathrm{kPa}$ evaporation pressure is $65.51^{\circ} \mathrm{C}$, while for $400 \mathrm{kPa}$ this value has risen to $83.54{ }^{\circ} \mathrm{C}$. The highest turbine inlet temperature value $(103.4$ ${ }^{\circ} \mathrm{C}$ ), constant $20{ }^{\circ} \mathrm{C}$ superheating temperature and $400 \mathrm{kPa}$ evaporation pressure.

Figure 6 shows the effect of evaporative pressure change on turbine work for different superheating temperature conditions. In all cases, as the evaporation pressure increases, the turbine work seems to increase. When the system without superheating was examined, the turbine work for the $250 \mathrm{kPa}$ evaporation pressure was $44.21 \mathrm{~kJ} / \mathrm{kg}$, while for $400 \mathrm{kPa}$ this value increased to $59.81 \mathrm{~kJ} / \mathrm{kg}$. For different superheating temperatures, the turbine work seems to give a closer result than the heat requirement.

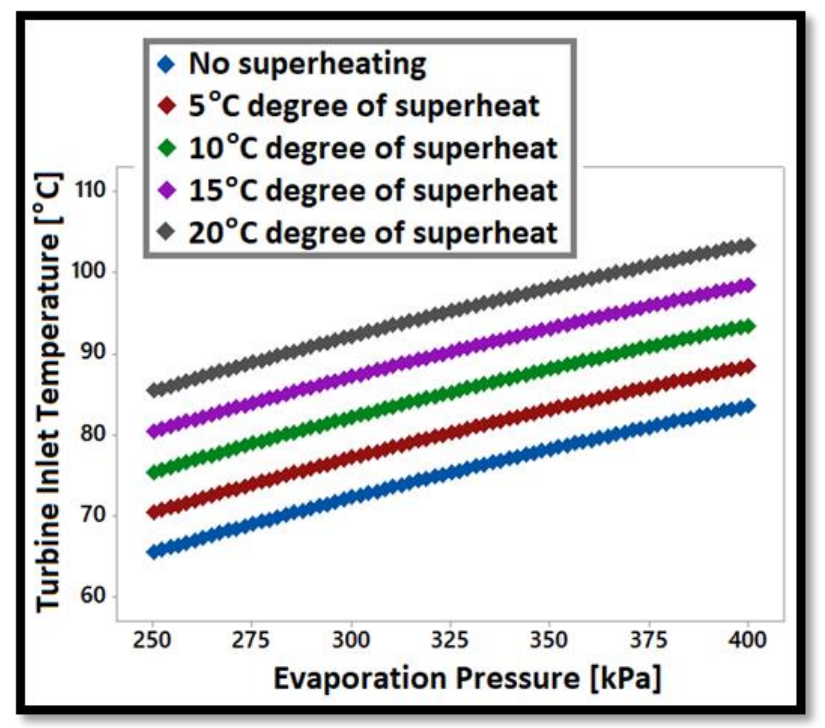

Fig. 5. Change of turbine inlet temperature with evaporation

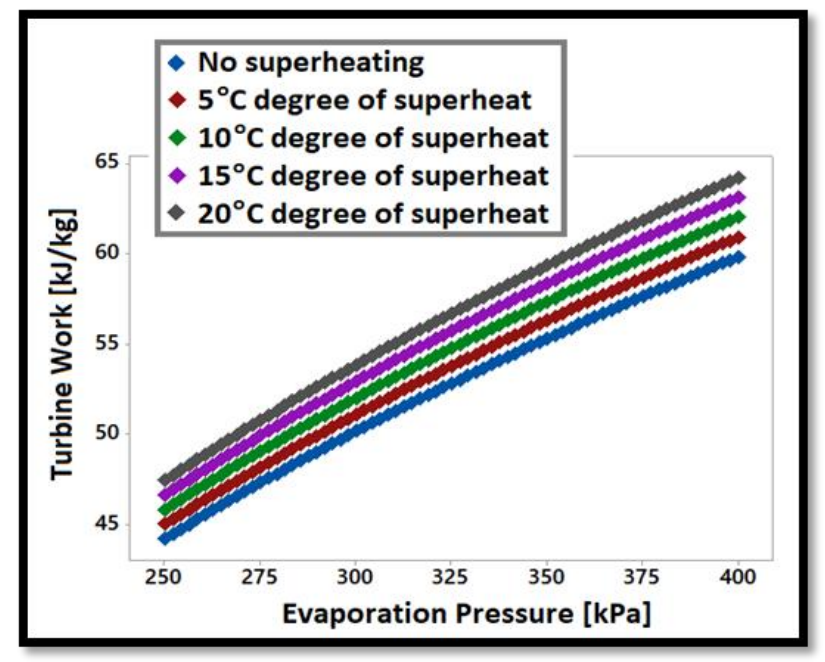

Fig. 6. Change of turbine work with evaporation pressure

Figure 7 shows the effect of evaporation pressure change on the turbine outlet temperature. As the evaporation pressure increases, the turbine outlet temperature increases. When the system without superheating is examined, the turbine outlet temperature for the $250 \mathrm{kPa}$ evaporation pressure is $36.07^{\circ} \mathrm{C}$, while for $400 \mathrm{kPa}$, this value has increased to $43.66^{\circ} \mathrm{C}$. For a $400 \mathrm{kPa}$ evaporation pressure, the turbine inlet temperature was reported to be $103.4{ }^{\circ} \mathrm{C}$ when the system had a constant $20{ }^{\circ} \mathrm{C}$ superheating temperature on Fig.4. Under the same values, the turbine outlet temperature was calculated as 64.19 ${ }^{\circ} \mathrm{C}$. 


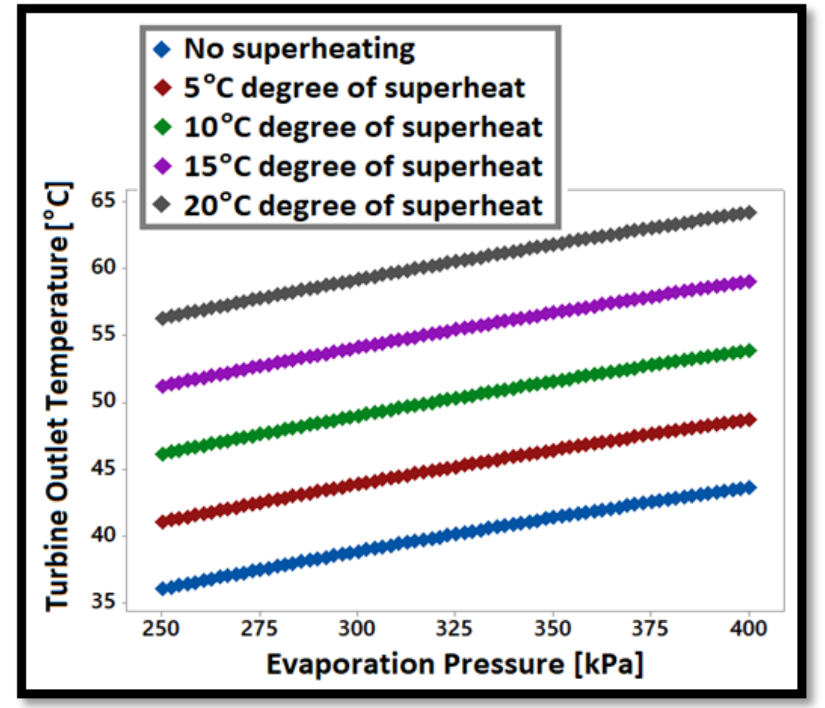

Fig. 7. Change of turbine outlet temperature with evaporation pressure

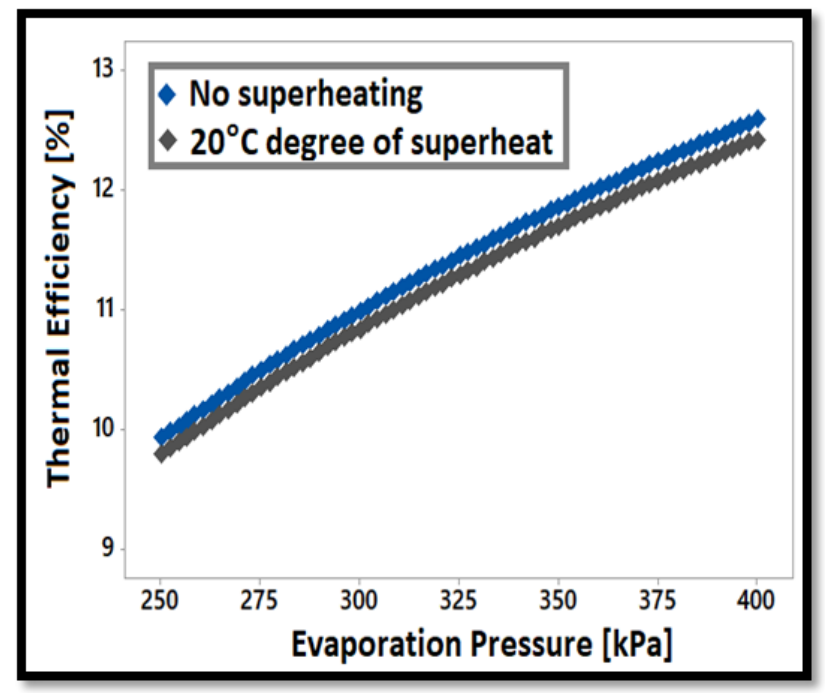

Fig. 8. Change of thermal efficiency with evaporation pressure

Figure 8 shows the effect of the evaporation pressure change on the thermal efficiency. As the evaporation pressure increases, the thermal efficiency increases. Since the different superheating temperatures give very close results, two situations have been mentioned that are more obvious. When the system without superheating was examined, the thermal efficiency for the $250 \mathrm{kPa}$ evaporation pressure was $9.93 \%$, while it increased to $12.59 \%$ for $400 \mathrm{kPa}$. When the system has a constant $20{ }^{\circ} \mathrm{C}$ superheating temperature, the thermal efficiency appears to drop slightly for all pressures. Figure 8 shows the effect of the evaporation pressure change on the thermal efficiency. As the evaporation pressure increases, the thermal efficiency increases. Since the different superheating temperatures give very close results, two situations have been mentioned that are more obvious. When the system without superheating was examined, the thermal efficiency for the $250 \mathrm{kPa}$ evaporation pressure was $9.93 \%$, while it increased to $12.59 \%$ for $400 \mathrm{kPa}$. When the system has a constant $20{ }^{\circ} \mathrm{C}$ superheating temperature, the thermal efficiency appears to drop slightly for all pressures.

II) MODEL-B

In the second model, the system performance was examined by changing the superheating temperature between $0{ }^{\circ} \mathrm{C}$ and $20{ }^{\circ} \mathrm{C}$. The thermodynamic design model is prepared separately for the following 4 different situations. For all cases, the amount of heat required for the system, turbine work, turbine inlet-outlet temperatures and thermal efficiency values are determined separately. With 100 input numerical test values, 500 numerical output values for each case were obtained. The analysis of model B was made with 2000 numerical output values for 4 different situations in total. These situations are;

- $250 \mathrm{kPa}$ evaporation pressure

- $300 \mathrm{kPa}$ evaporation pressure

- $350 \mathrm{kPa}$ evaporation pressure

- $400 \mathrm{kPa}$ evaporation pressure

Figure 9 shows the effect of superheating temperature change on the amount of heat requirement for different evaporation pressure $(\mathrm{Pe})$ conditions. In all cases, as the superheating temperature increases, the system seems to require more heat. For a $250 \mathrm{kPa}$ constant evaporation pressure, the heat requirement for the system is $441.4 \mathrm{~kJ} / \mathrm{kg}$ when there is no superheating, while this value rises to $480.7 \mathrm{~kJ} / \mathrm{kg}$ when the superheating temperature is $20^{\circ} \mathrm{C}$.

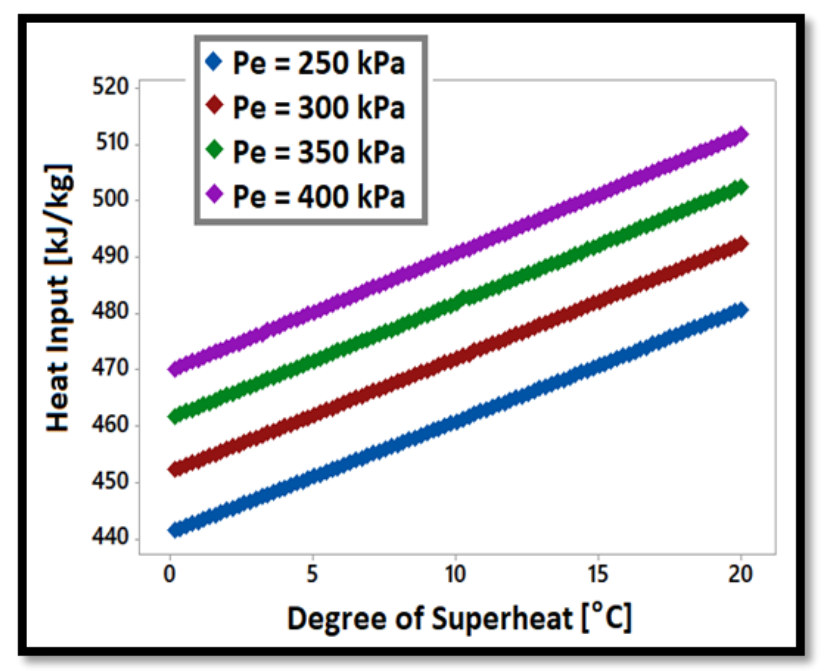

Fig. 9. Change of heat input with superheating temperature

Figure 10 shows the effect of superheating temperature change on turbine inlet temperature for different evaporative pressure situations. For $250 \mathrm{kPa}$ constant evaporation pressure, the turbine inlet temperature is $65.41^{\circ} \mathrm{C}$ when there is no superheating, while this value increases to $85.41^{\circ} \mathrm{C}$ with $20{ }^{\circ} \mathrm{C}$ superheating temperature. 


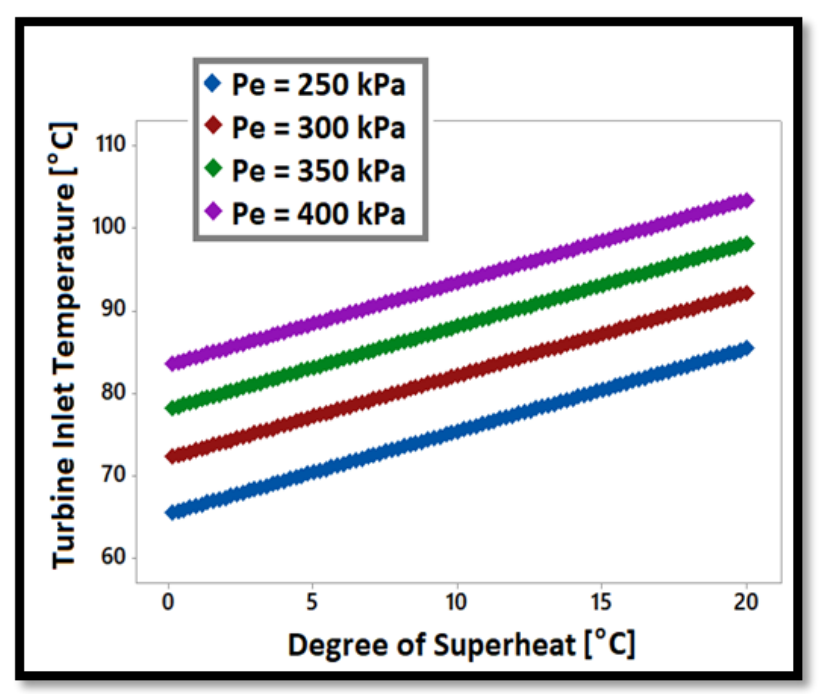

Fig. 10. Change of turbine inlet temperature with superheating temperature

Figure 11 shows the effect of the superheating temperature change on turbine work for different evaporation pressure states. In all cases, the turbine work seems to increase as the superheating temperature increases. For $250 \mathrm{kPa}$ constant evaporation pressure, turbine work value is $44.21 \mathrm{~kJ} / \mathrm{kg}$ when there is no superheating, while this value increases to 47.45 $\mathrm{kJ} / \mathrm{kg}$ when it is $20^{\circ} \mathrm{C}$ superheating.

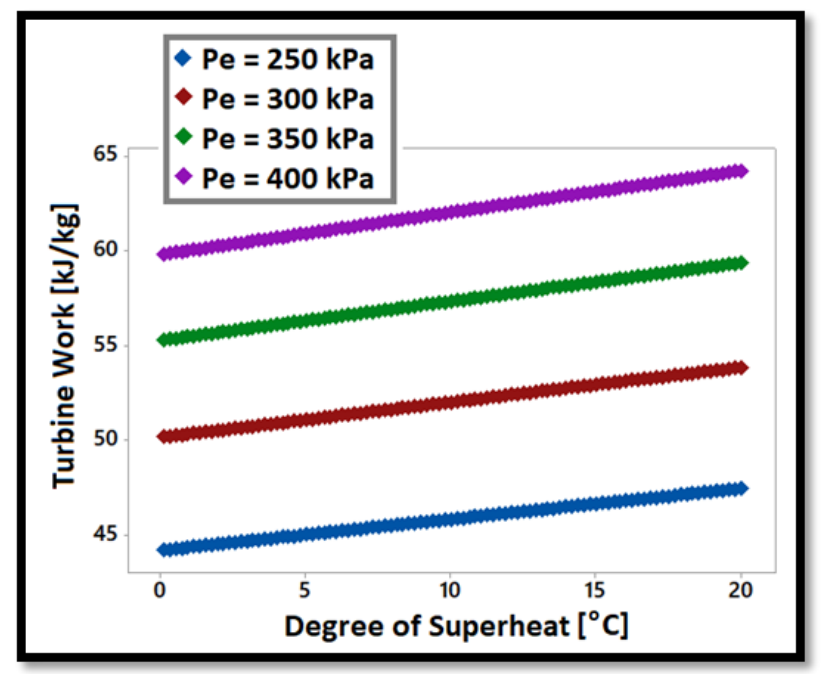

Fig. 11. Change of turbine work with superheating temperature

Figure 12 shows the effect of the superheating temperature change on the turbine outlet temperature for different evaporation pressure states. In all cases, the temperature of the turbine outlet increases as the superheating temperature increases. For a $250 \mathrm{kPa}$ constant evaporation pressure, when there is no superheating, the turbine outlet temperature is $36.07{ }^{\circ} \mathrm{C}$, while at $20{ }^{\circ} \mathrm{C}$ superheating, this value rises to $56.29^{\circ} \mathrm{C}$.

Figure 13 shows the effect of the superheating temperature change on the thermal efficiency for different evaporation pressure states. For all cases, it is seen that as the superheating temperature increases, the thermal efficiency decreases slightly. For $250 \mathrm{kPa}$ constant evaporation pressure, the thermal efficiency is $9.93 \%$ when there is no superheating, while it decreases to $9.79 \%$ when the superheating temperature is $20^{\circ} \mathrm{C}$.

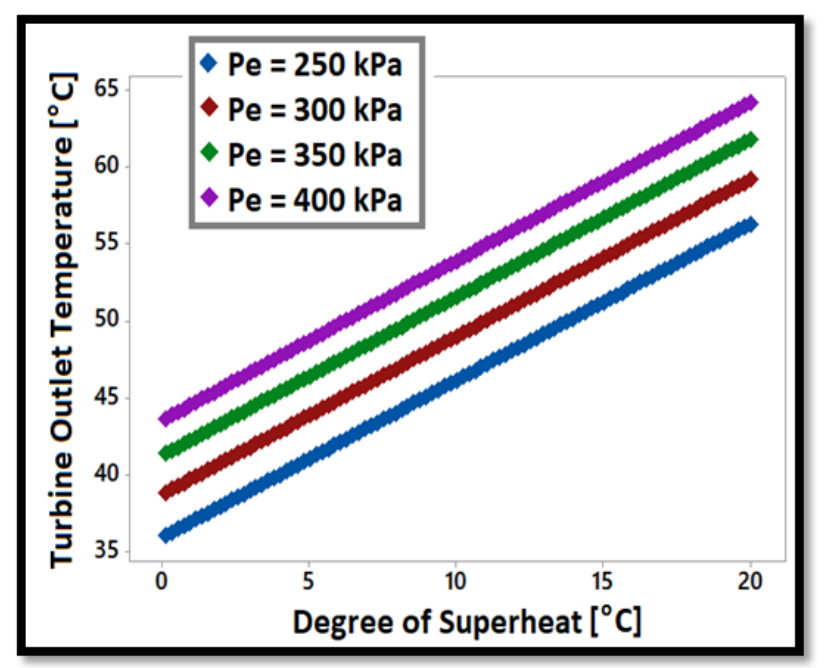

Fig. 12. Change of turbine outlet temperature with superheating temperature

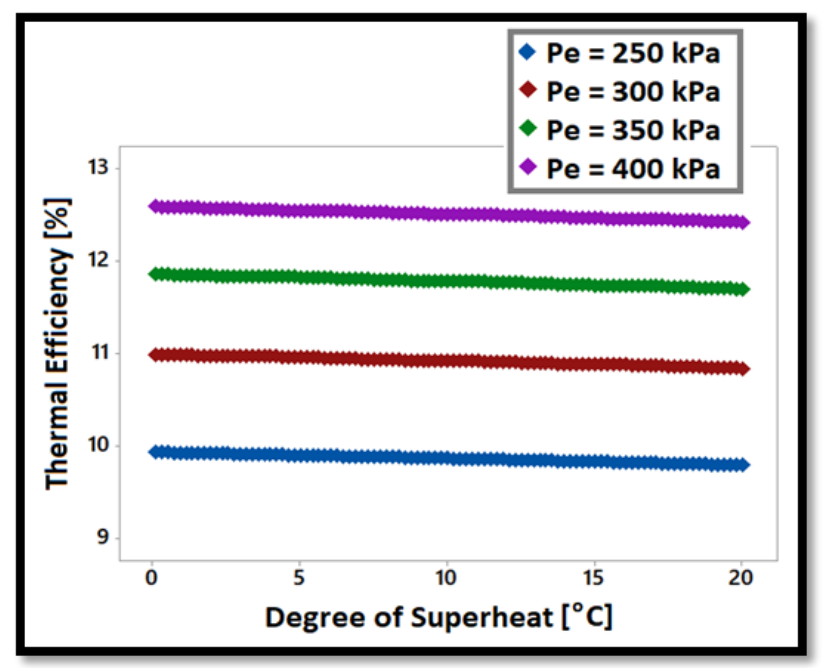

Fig. 13. Change of thermal efficiency with superheating temperature

\section{Conclusion}

In this study, the energy analysis of the n-pentane fluid, which is used too much as the organic fluid in ORC application, is done. On the n-pentane fluid, the effect of evaporation pressure and superheating temperature was evaluated with two different models prepared. The thermodynamic design model is based on the integrated use of EES.

Five different situations were analyzed in the prepared first model. The effect of the evaporation pressure on the system at different superheating temperatures is determined. If the first case without superheating is taken into consideration, increasing the $250 \mathrm{kPa}$ evaporation pressure to $400 \mathrm{kPa}$ 
increases the thermal efficiency of the system from $9.93 \%$ to $12.59 \%$. However, the amount of heat requirement for the system increases from $441.4 \mathrm{~kJ} / \mathrm{kg}$ to $470.1 \mathrm{~kJ} / \mathrm{kg}$. When the system with $5{ }^{\circ} \mathrm{C}$ superheating temperature is considered, the thermal efficiency has increased from $9.90 \%$ to $12.55 \%$ as the evaporation pressure is increased from $250 \mathrm{kPa}$ to 400 $\mathrm{kPa}$. The amount of heat required for the system increases from $451 \mathrm{~kJ} / \mathrm{kg}$ to $480.2 \mathrm{~kJ} / \mathrm{kg}$. Evaporation pressure was found to increase the thermal efficiency of the system at all constant superheating temperatures, but at the same time it increased the amount of heat requirement in the system. In the second model, the evaporation pressures are assumed to be constant and the effect of superheating temperatures is discussed in more detail. Four different situations have been analyzed. For the $250 \mathrm{kPa}$ constant evaporation pressure, the thermal efficiency of the system without superheating is $9.93 \%$, while the thermal efficiency at the $20^{\circ} \mathrm{C}$ superheating temperature is $9.79 \%$. For the $400 \mathrm{kPa}$ constant evaporation pressure, the thermal efficiency of the system with no superheating is $12.59 \%$, while the thermal efficiency at $20^{\circ} \mathrm{C}$ superheating temperature is $12.42 \%$. It has been seen that the increase of the superheating temperature slightly reduces the thermal efficiency value at all constant pressure values.

As a result, it is presented that the energy analysis of the ORC system containing n-pentane fluid can be successfully applied with the thermodynamic design model developed with EES in this study.

Acknowledgments

This study constitutes part of the ongoing PhD thesis of Sadik Ata.

\section{References}

[1] Ağırkaya, O., 2015, "Jeotermal Enerji Kaynaklı Organik Rankine Çevriminin Modellenmesi ve Analizi", Master Thesis, İstanbul Teknik University, Graduate School of Natural Sciences, İstanbul, Turkey.

[2] Kaska, O., 2014, "Energy and exergy analysis of an organic Rankine for power generation from waste heat recovery in steel industry", Energy Conversion and Management, 77, 108-117.

[3] Lecompte, S., Ameel, B., Ziviani, D., Broek, M., Paepe, M., 2014, "Exergy analysis of zeotropic mixtures as working fluids in Organic Rankine Cycles", Energy Conversion and Management, 85, 727-739.

[4] Le, V., Feidt, M., Kheiri, A., Pelloux-Prayer, S., 2014, "Performance optimization of low-temperature power generation by supercritical ORCs (organic Rankine cycles) using low GWP (global warming potential) working fluids", Energy, 67, 513-526.

[5] Javanshir, A., Sarunac, N., 2017, "Thermodynamic analysis of a simple Organic Rankine Cycle", Energy, $118,85-96$.
[6] Li, L., Ge, Y., Tassoua, S., 2017, “Experimental Study on a small-scale R245fa Organic Rankine cycle system for low-grade thermal Energy Recovery", Energy Procedia, $105,1827-1832$.

[7] Wang, H., Li, H., Wang, L., Bu, X., 2017 , "Thermodynamic Analysis of Organic Rankine Cycle with Hydrofluoroethers as Working Fluids", Energy Procedia, 105, 1889-1894.

[8] Li, J., Liu, Q., Ge, Z., Duan, Y., Yang, Z., 2017, "Thermodynamic performance analyses and optimization of subcritical and transcritical organic Rankine cycles using R1234ze(E) for $100-200^{\circ} \mathrm{C}$ heat sources”, Energy Conversion and Management, 149, 140-154.

[9] Feng, Y.Q., et al., 2017, “Operation characteristic of a R123-based organic Rankine cycle depending on working fluid mass flow rates and heat source temperatures", Energy Conversion and Management, 131, 55-68.

[10] Tchanche B.F., 2010, "Low-Grade Heat Conversion into Power Using Small Scale Organic Rankine Cycles", Doctoral Thesis, Department of Natural Resources and Agricultural Engineering, Agricultural University of Athens, AUA.

[11] Calm J.M., Hourahan, G.C., 2007, "Refrigerant Data Update", Heating/Piping/Air Conditioning Engineering, 79(1), 50-64. 